\title{
VICISITUDES DE LA SEMIÓTICA Y DE LA NARRATOLOGÍA EN EL ÁMBITO DEL HISPANISMO INTERNACIONAL $(1980 / 89)$
}

Georges Güntert

Universidad de Zurich

Al tratar de comparar las tendencias dominantes en los trabajos de teoría literaria realizados durante las décadas de los setenta, por un lado, y de los ochenta, por otre, se nos revelan unas constantes que convergen en los siguientes tres puntos:

1) la investigación en torno al discurso, objeto de estudio que se halla hoy en el punto de confluencia de distintas disciplinas;

2) la atención concedida a las pasiones, ante todo en el ámbito de la teoría de la comunicación, donde cabe redefinir la relación entre persuadir e informar, creer y conocer; $\mathrm{y}$

3) el debate sobre la función estética de la literatura, llamada por algunos literariedad y por otros poeticidad, sin que haya siempre unidad de doctrina.

1. En los últimos años el interés de los investigadores parece haberse desplazado desde el estudio de los significados al de la producción de los mismos, esto es, de lo narrado al acto y a los modos de narrar, de la historia al sujeto que la emite o a los tipos de lectores que la experimentan, del enunciado al proceso de enunciación. En el centro de la atención crítica se colocan hoy conceptos tales como enunciación, narración y focalización por un lado; discurso, veridicción y figurativización por otro.

De lo cual sacamos una primera constatación, esto es, que la narratología sigue con buena salud y con ininterrumpido dinamismo. Es verdad que mucho de lo que se lee ahora es aplicación, ampliación y a veces mera 
repetición de las tesis de Genette o de Bal. Pero, pese a esto, puede decirse que la disciplina ha progresado: en el ámbito del hispanismo, concretamente, se ha investigado - con provecho- en torno al concepto de focalización, arrojando nueva luz sobre la semiótica del discurso referido ${ }^{1}$; se ha profundizado en el estudio de las relaciones entre la estructura comunicativa de los textos y los géneros literarios ${ }^{2}$; se han establecido contactos entre la semiótica y la estética de la recepción ${ }^{3}$; se ha explorado la estrategia retórica del diálogo $\mathrm{A}^{4}$ se ha intentado definir - con criterios narratológicos y bajtinianos-el concepto de ironía ${ }^{5}$; se ha teorizado sobre el sentido de lo visible $y$, en especial, sobre el del espectáculo ${ }^{6}$; se han hecho nuevas propuestas

J. L. Rivarola y Susana Reisz de Rivarola, "Semiótica del discurso referido", en Homenaje a Ana María Barrenechea, ed. por L. Schwartz Lerner e I. Lerner, Madrid, Castalia, 1984, pp. 151-174 (estudio en el que se desarrollan algunos presupuestos de G. Genette y de $\mathbf{M}$. Bal, así como de la lingüística textual alemana). Véase, además, de la misma autora "Voces y conciencias modalizantes en el relato literariom, en AA.VV., Teoria semiótica. Lenguajes y textos hispánicos (Actas del I Congreso Internacional sobre Semiótica e Hispanismo), Madrid, CSIC, 1984, I, pp. 561-584. Sobre el concepto de focalización cfr. también F. Martínez-Bonati, "El sistema del discurso y la evolución de las formas narrativas», Dispositio, V-VI, 15-16, 1980/ 81, pp. 1-18; M. Rojas, "Tipología del discurso del personaje en el texto literario", Dispositio. V-VI, 15-16, 1980/81, pp. 19-55; P. Rubio de Lértora, «Niveles y sujetos de focalización en Pedro Páramo", Semiosis, 14/15, 1985, pp. 152-166, etc.

- Sobre distanciamiento entre el yo enunciador y el yo actor en el discurso lírico cfr. A. García Berrio, "Lingüística del texto y texto lírico (La tradición textual como contexto)», $R S E L, 8,1,1978$, pp. 19-75; y del mismo autor: «Testo, classe testuale, genero», en VV.AA., Diacronia, Sincronia e Cultura. Saggi linguistici in onore di Luigi Heilmann, Brescia, La Scuola, 1984, pp. 267-280. H. Urrutia Cárdenas trata de extender esta reflexión a los demás géneros en "Situación comunicativa y texto literario», Revista Española de Lingüística, 9, 1, 1979, pp. 191-199. Cfr. también J. M. Pozuelo Yvancos, "Teoría de los géneros y poética normativa", Teoria semiótica. Lenguajes y textos hispánicos (Actas del Congreso Internacional sobre Semiótica e Hispanismo), op. cit.. I, pp. 393-401; Teoría de los géneros literarios, ed. por M. A. Garrido Gallardo, Madrid, Arco Libros, 1988 (con contribuciones de G. Genette, T. Todorov, W. D. Stempel, Ch. Brooke-Rose y N. Salvador Miguel).

${ }^{3}$ Iris M. Zavala combina elementos de la teoría semiótico-narratológica (lindtvelt) con otros de la estética de la recepción (Jauss, Iser, Stierle) en su estudio Lectura y lectores del discurso narrativo dieciochesco, Amsterdam, Rodopi, 1987.

4 AA.VV., "La semiótica del diálogo», Diálogos Hispánicos de Amsterdam, n. ${ }^{\circ}$ 6, Amsterdam, 1987.

'C. Peña-Marín, «Interacción y polifonía en la ironia», en Teoria semiótica, op. cit., I, pp. 287-294, donde se cita a W. C. Booth, Retórica de la ironia, Madrid, Taurus, 1986. Sobre la concepción irónica del Quijote (en el nivel de la enunciación) trata G. Güntert, «Dos motivos recurrentes, dos héroes y una aventura común", en Romania ingeniosa, Festschrift G. Hilty, ed. por G. Lüdi, H. Stricker y J. Wüest, Berna, Lang, 1987, pp. 303-318.

A. Risco, Literatura y figuración, Madrid, Gredos, 1982 (concluido en 1975); J. Urrutia, Semio $\{p$ ) tica. Sobre el sentido de lo visible. Madrid, F. I. Shakespeare, Instituto de Cine y Radio-Televisión, 1985; y, con un enfoque algo diferente, J. P. Buxó, La figuración del sentido, México, 1988; A. Garcia Berrio y M." T. Hernández Fernández, Ut poesis pictura. Poética del arte visual, Madrid, Tecnos, 1988.

Sobre la semiótica del teatro cfr. José M. Díez Borque y L. García Lorenzo (ed.), Semiología del teatro, Barcelona, Planeta, 1975; R. Durand, «Problèmes de l'analyse structurale et sé- 
de nomenclatura para la instancia que organiza y maneja la enunciación total de la obra: «enunciador o sujeto de la enunciación», según Greimas, «hablante (y destinatario) implícitos» para Todorov y H. Urrutia-Cárdenas, "autor implicito" o "autor interno" para quienes no quieren comprender que también en este último nivel es necesario suponer un eje de comunicación ${ }^{7}$. La variedad de los enfoques, además de manifestarse año tras año en la actividad de las revistas especializadas (Semiosis, Lexis, Revista de Literatura, Archivum, Discurso, Lingüistica Española Actual, etc.), queda decumentada en los dos imponentes tomos de las Actas del I Congreso Internacional sobre Semiótica e Hispanismo, celebrado en 1983 en Madrid8. Desde entonces, la Asociación Española de Semiótica, fundada en 1984 gracias al empeño de José Romera Castillo, ha convocado congresos nacionales en Toledo, Oviedo y Madrid, cuyas actas han sido (o van a ser) publicadas.

Por otra parte, se percibe en la actualidad una innegable mengua de interés por los modelos narrativos. Comienzan a escasear las tentativas encaminadas a definir un único modelo, con la pretensión de poder analizar con él cualquier clase de cuento, bien sea literario o popular, tradicional o moderno. Tampoco es fácil encontrar hoy, a no ser en los manuales que

miotique de la forme théâtrale», en AA.VV., Sémiologie de la représentation, ed. por A. Helbo, Bruselas, Complexe, 1975; G. Bettetini, Teatro e comunicazione, Firenze, Le Guide Guiraldi, 1977; M. de Marinis, Semiotica del teatro. L'analisi testuale dello spettacolo, Milán, Bompiani, 1982; M. Sito Alba, Análisis de la semiótica teatral, Madrid, UNED, 1987; F. de Toro, Semiótica del teatro. Del texto a la puesta en escena, Buenos Aires, Galerna, 1987; J. Romera Castillo, Semiótica literaria y teatral en España, Kassel, Reichenberger (Problemata Semiótica, 14), 1988; C. Segre, «Semiotica e teatro», Versants, 14, 1988, pp. 3-11.

' Merece la pena reproducir la distinción propuesta por H. Urrutia-Cárdenas, en «Situación comunicativa y texto literario», op. cit., p. 198: "La enunciación es la actualización peculiar del discurso; en toda obra literaria puede darse una serie de enunciaciones a cargo de distintos emisores ficticios, pero siempre hay una enunciación total que organiza y proyecta una perspectiva valorativa global. A la fuerza comunicativa que la sostiene se le llama hablante implicito.» Este último término corresponde al de aenunciador» o "sujeto enunciante" que empleamos en esta reseña. Sobre las posibles denominaciones del sujeto de la enunciación cfr. también R. Prada Oropeza, "Los elementos pragmáticos del discurso narrativo: el narrador y el narratario», Semiosis, 14/15, 1985, pp. 3-35; y E. Frechilla Díaz, "Las instancias de enunciación del texto literario», Lingüistica Española Actual, 8, 1986, pp. 187-194.

' AA.VV., Teoria semiótica. Lenguajes y textos hispánicos..., op. cit. (cfr. nota 1). Cfr. la reseña de L. Albuquerque, "La semiótica literaria en el ámbito hispánico", Lingüistica Española Actual, VIII, 2, 1986, 269-272. En cuanto a las actas de la AES (Asociación Española de Semiótica), son las siguientes: Investigaciones Semióticas (sobre teoría semiótica), Madrid, CSIC, 1986; Investigaciones Semióticas II (sobre el teatro), Oviedo, Univ. de Oviedo, 1988, 2 vols.; Investigaciones Semióticas III. Retórica y lenguajes, Madrid, Universidad Nacional de Educación a Distancia, 19902 vols. Una ampliación bibliográfica de los trabajos de semiótica literaria y teatral realizados en España (hasta junio de 1988) la ofrece J. Romera Castillo, "Semiótica literaria y teatral en España. Addenda bibliográfica», en Homenaje a Ignacio Elizalde. Estudios literarios, Bilbao, Universidad de Deusto, 1989, pp. 269-286; además de su libro, Semiótica literaria y teatral en España, op. cit. 
reproducen los métodos canónicos de hace quince o veinte años, el tipo de análisis que trate de reducir la complejidad del texto literario al esquema de las funciones de Propp o a los modelos más bien rudimentarios de un Brémond, un Todorov o del primer Greimas, aunque algunos insistan en que se mantenga el modelo actancial greimasiano, por su utilidad extendida al estudio de la enunciación'. La necesidad de suponer una pluralidad de modelos narrativos es, por tanto, ya un hecho reconocido ${ }^{10}$. También comienza a aceptarse la noción de que cualquier estudio de los significados (o valores) enunciados ha de ir acompañado de una reflexión sobre los procedimientos enunciativos, garantes de la transmisión de aquéllos. $\mathrm{O}$ dicho de otro modo: los valores son cuestión tanto de la historia narrada como del pacto narrativo, ya que el mensaje que el sujeto enunciador transmite al lector no puede ser sino un mensaje cargado de valores.

Pero ¿cuál es la causa del desinterés por los modelos narrativos? Con la difusión de los escritos de Bajtín se ha impuesto la distinción entre textos monológicos (como el cuento de hadas, condicionado por un único sistema de valores) y textos dialógicos, tales como la novela moderna, la poesía o el drama contemporáneos, en los que contrastan diferentes sistemas de valores o, como hoy se dice, diferentes Discursos ${ }^{11}$. Un modelo, como el de Propp, concebido para analizar un cierto número de cuentos populares, no es adecuado, por tanto, para la comprensión de los textos literarios complejos, cuyo sentido, por otra parte, no podría captarse sin tener en cuenta los procedimientos de la enunciación.

En cuanto al término discurso, es verdad que su definición dista mucho de ser univoca. A mi entender, pueden distinguirse por lo menos tres acepciones: a) algunos lingüistas (Benveniste, Hendricks) llaman discurso a lo que va más allá de la oración, a los enunciados transfrásticos, a la suma orgánica de oraciones o a las relaciones entre éstas y el contexto; b) en el ámbito semiótico, en cambio, es discurso el texto concebido en su actualización, como estructura organizada (por un sujeto); y existen, por fin, c) los Discursos, con letra mayúscula, con los cuales se designan las ideologías, modos de pensar o sistemas de creencias que constituyen nuestra realidad

9 Significativamente, un estudio «proppiano» realizado en estos últimos años en España se centra en el análisis de una colección de cuentos de hadas: $M$. de Andrés Gutiérrez, «Ensayo de análisis estructural del cuento", Bulletin Hispanique, LXXXVI, 1984, 3-4, pp. 403-434. Una defensa del modelo de Brémond se encuentra en el estudio de M." Dolores Rajoy Feijoo, "La aproximación crítica. El cuento popular y el cuento literariom, Archivum, XXXIV-XXXV, 1984/85, pp. 207-215.

${ }_{10}$ P. Paioni, J. Geninasca, P. Fabbri y R. Ceserani, "Narrativi possibili», en AA.VV., Narrare: percorsi possibili, ed. por M. di Fazio, Ravenna, Longo, 1989, pp. 242-254.

" M. Bakhtine, Esthétique et théorie du roman; Paris, Gallimard, 1978, que contiene el escrito (redactado en 1934/35) «El discurso en la novela». Sobre el concepto de "pluridiscursividad». Cfr. C. Segre, "Intertestuale - Interdiscorsivo. Appunti per una fenomenologia delle fonti", en La parola ritrovata, Palermo, Sellerio, 1982, pp. 15-28. 
(Discurso científico vs mítico, esto es mítico-religioso, mítico-poético, etc.). Para definir la especificidad de un Discurso, en esta última acepción, es necesario precisar: 1) el tipo de creencias que determine las relaciones entre el sujeto y el orden de los valores; y 2) el modo de racionalidad que le corresponda (esto es, la competencia de aprehender y organizar la pluralidad de los significados para poder reducirlos a una concepción unitaria del mundo). Con esto quiero hacer constar que existen diferentes formas de racionalidad: es evidente que la racionalidad propia del discurso mitico, al que pertenecen la poesía, la literatura, la pintura, la música, etc., no es del mismo tipo que la del discurso positivista científico. De ahí el carácter problemático de ciertas disecciones con que los críticos más «algebristas» de los años setenta quisieron desmontar las obras de arte; y de ahí, también, la dificultad en comprender gran parte de la poesía moderna (futurismo, surrealismo, hermetismo, etc.), cuyo estudio exige la adopción de categorías críticas especiales, diferentes de las propuestas por la semiótica de los orígenes ${ }^{12}$.

2. Nuestra reflexión sobre el discurso ha puesto de relieve el protagonismo que desempeñan en la teoría literaria las creencias. Y con esto llegamos al segundo punto: en la actualidad se tiende a revalorizar la modalidad del creer, que debe considerarse como algo primordial y anterior a todo esfuerzo cognoscitivo. Todas las operaciones que emprendamos se fundamentan en un conjunto de creencias, y la asunción consciente de ellas representa siempre un paso ya ulterior, más avanzado. Ahora bien, si nuestras actividades proceden de un creer, gran parte de las teorias semiológicas de los años setenta deben ser revisadas, y veo aqui una de las principales reformas que precisará la semiótica del porvenir. Por otra parte, la ventaja de esta situación podría ser la posibilidad de un diálogo entre la semiótica y pensadores como Schopenhauer y Freud, diálogo que se anuncia, desde luego, muy prometedor ${ }^{13}$.

12 Escribe a propósito de esta dificultad J. Geninasca: «A l'opposé de la saisie poétique ou esthétique du monde, on le sait, s'est développée une forme de rationalité "cartésienne" qui vise à exclure le pathémique de l'ordre de la pensée, à poser l'existence du sujet, à assurer son pouvoir-croire à fonder la réalité du monde, en toute indépendance des affects qui caractérisent l'existence modale. Il en résulte l'illusion d'un monde indépendant du sujet et le malheur d'un sujet étranger au monde, à autrui et à soi. En dépit de ses ambitions cognitivistes, la sémiotique s'est paradoxalement intéressée, en premier lieu, aux discours qui relèvent d'une rationalité mythique, poétique, esthétique; il lui faut aujourd'hui penser et élaborer les rapports que peuvent entretenir les diverses "rationalités"»; en J. Geninasca, «Une chimie des passions est-elle pensable?», VS, Quaderni di studi semiotici, 47/48, mayo-diciembre, 1987, p. 101. La noción de «pluralidad de racionalidades» se impuso en Francia a partir del estudio AA.VV., Divination et rationalité, París, Seuil, 1974.

${ }_{13}$ En este sentido se mueve desde hace tiempo la investigación de J. Kristeva, La révolution du langage poétique, Paris, Seuil, 1974; e id., Soleil noir. Dépression et mélancolie, Paris, Gallimard, 1987. 
Por la misma razón, se atribuye hoy mayor peso a la influencia de las pasiones, en el nivel tanto de la enunciación como del enunciado ${ }^{14}$. En este terreno, en particular, el hispanismo puede ofrecer estudios muy valiosos: el de M." Grazia Profeti sobre La escritura y el cuerpo o el de Monique Joly sobre el tema culinario en La Lozana Andaluza - y se trata de dos ejemplos entre otros- ${ }^{15}$. Si bien nos falta, de momento, una teoria moderna de los afectos o una gramática de las pasiones, sabemos que todo proceso de comunicación literaria $y$, por tanto, de recepción o lectura depende - si no de una voluntad de ilusionar- de un acto de persuasión, es decir, de un hacer persuasivo ${ }^{16}$. No hay obra literaria cuyo proceso informativo -el hacer saber - no vaya acompañado de otro, consistente en un hacer creer (piénsese no sólo en la transmisión de los conceptos, sino también en la fuerza persuasiva del ritmo, que crea tensión, espera o satisfacción implicando ante todo a las pasiones). Tal proceso comporta el adherirse a la realidad textual por parte del lector, quien se somete a los efectos de la

14 Data de 1983 la traducción española del primer estudio greimasiano sobre las pasiones: A. J. Greimas, «Para una semiótica de las pasiones», Semiosis, 10, pp. 3-9. En el mismo año aparece en Francia «De la colère. Étude de sémantique lexicale», Du Sens II, París, Senil, 1983. Sigue, el ensayo «De la nostalgie, Etude de Semantique lexicale», en Les passions. Explorations sémiotiques, ed. por D. Bertrand, Actes sémiotiques. Bulletin, XI, 39, 1986. De notable interés es el volumen AA.VV., De la croyance. Approaches épistémologiques et sémiotiques, ed. por $\mathrm{H}$. Parret, Berlín/Nueva York, De Gruyter, 1983. Parret es también autor del volumen Les passions. Essai sur la mise en discours de la subjectivité, Liège, Mardaga, 1986. Otros trabajos sobre la teoria de las pasiones se encuentran en P. Fabbri-J. Lozano-J. Manetti, La persuasione: modelli ed analisi sui funzionamenti discorsivi nelle comunicazioni di massa, Turín, RAI, $\mathrm{n} .{ }^{\circ} 365$, 1981 y en un número reciente de la revista italiana de estudios semióticos $V S, 47 / 48$ (con un estudio de C. Peña-Marín sobre «Razón, pasión e identidad» y colaboraciones de $\mathrm{D}$. Bertrand, P. Fabbri, L. Marín, etc.). A L. Marín le debemos una Sémiotique de la passion, topiques et figures, París, Aubier-Montaigne, 1978. Fuera del ámbito semiológico, cfr., ante todo, el estudio, ya clásico, de J. P. Sartre, Esquisse d'une théorie des émotions, París, Herrmann, 1965 (pero escrito en 1938) y otro reciente de M. Meyer, Rhétorique des passions, selon Aristote, París, Rivages, 1989. Son numerosos los enfoques de tipo psicológico: por ejemplo, R. C. Solomon, The Passions, Nueva York, Anchor Press, 1977; R. de Sousa, "The rationality of emotions», en A. O. Rorty, Explaining emotions, Berkeley, Univ. of California Press, 1980; N. Luhmann, Liebe als Passion. Zur Codierung von Intimität, Francfort, Suhrkamp, 1982; у M. Johnson, The body in the mind, Chicago, Univ. of Chicago Press, 1987.

is M." Grazia Profeti, La scrittura e il corpo, Roma, Bulzoni, 1984; y M. Joly, "A propósito del tema culinario en la Lozana Andaluza), ponencia dictada en el X Congreso AIH, Barcelona, 1989 (se prevé la publicación de las actas). Acerca de estos temas cfr. también un número especial de la revista alemana Zeitschrift für Semiotik, IV, 1982, 4, sobre "Kulinarische Semiotik» (con varias contribuciones).

16 Sobre las concepciones opuestas de Jakobson (concepción mecanicista) y de Greimas (manipulación, interacción) con respecto a la comunicación literaria, cfr. los dos estudios de G. Latella, "Semiótica greimasiana y teoría de la comunicación», Archivum, XXXI-XXXII (1981/82), pp. 451-462, y «Enfoque semiótico de la interacción», Lingüistica Española Actual, VIIl, 2, 1986, pp. 169-175. Aporta nuevos elementos a una teoria de la comunicación el estudio de J. Geninasca, «Notas sobre la comunicación epistolar», Revista de Occidente, 1989, pp. 6580 . 
manipulación tanto más espontáneamente en cuanto que éstos suelen ser placenteros.

Pues bien, si la literatura es obra no tanto informativa cuanto persuasiva, ¿cual podrá ser el tipo de verdad que ella nos comunica? La discusión en torno a la verdad de la literatura sigue animada, no sin tropiezos y recaídas. Se trata ante todo de evitar la confusión entre los conceptos dispares de verdad (afirmada por el texto, por medio de un acto de veridicción) y de verosimilitud, la cual resulta del acto persuasivo de las instancias narrativas, deseosas de obtener un efecto inmediato de credibilidad ${ }^{17}$.

No han desaparecido, por supuesto, los críticos que sostienen la función referencial del lenguaje literario, buscando trazas de la "verdad fáctica» incluso en las obras más elaboradas o suponiendo la (imposible) identidad entre el autor y su personaje. Otros vuelven a proponer la concepción, algo inveterada, de la obra como "reflejo» de la vida social. Y aun otros, remontándose a las teorias aristotélicas, distinguen entre lo fáctico, lo verosímil, lo posible y lo imposible (o irreal) de un texto, considerando estos aspectos principalmente desde la perspectiva del lector ${ }^{18}$; lo cual ha dado buenos resultados en el campo de los estudios sobre la literatura fantástica ${ }^{19}$.

En contra de una concepción positivista del lenguaje, se va imponiendo hoy una tendencia opuesta, reacia a la idea de referencialidad en el discurso literario. Quienes la rechazan se ven precisados a meditar en el modo particular de la comunicación literaria, porque, al negarse el referente, la producción de los significados - y, por tanto, de toda verdad - ha de ocurrir en el ámbito mismo de la comunicación intratextual, como resultado de una interacción, y señaladamente de un acto de veridicción, atribuible al sujeto enunciante (o al narrador delegado). Éstos se valen del carácter figurativo del lenguaje - y concretamente, de las figuras del mundo- para crear una realidad puramente literaria, pero semejante a la del mundo y, por tanto,

1 En su estudio "Les actants, les acteurs et les figures" (Sémiotique narrative et textuelle, París, Larousse, 1973), A. J. Greimas habla de la "verdad intrinseca del relato" producida por un acto de veridicción. Al usar este término intenta subrayar que, en los discursos, los enunciados no tienen verdad en sí, sino que ésta es construida por un sujeto enunciante y aparece como efecto de un proceso semiótico. Del mismo autor cfr. "Le contrat de véridiction", $D u$ Sens II; París, Seuil, 1983. Acerca de la problemática de la veridicción cfr. el comentario esclarecedor de J. Lozano, C. Peña-Marin, G. Abril, Análisis del discurso. Hacia una semiótica de la interacción textual, Madrid, Cátedra, 1986, pp. 76-81.

${ }_{18}$ S. Reisz de Rivarola, Teoria literaria. Una propuesta, Lima, PUCP, 1986, en especial el cap. VII sobre "Literatura y ficción».

is A. M. Barrenechea, "Ensayo de una tipología de la literatura fantástica", en Textos hispanoamericanos. De Sarmiento a Sarduy. Caracas, Monte Ávila, 1974, pp. 87-103, y de la misma autora: "La literatura fantástica: función de los códigos culturales en la constitución del género", Instituto Internacional de Literatura Iberoamericana, Texto/contexto en la literatura iberoamericana (Memoria del XIX Congreso, Pittsburgh), ed. por K. McDuffie y A. Roggiano, Madrid, 1980; A. Risco, "La narración fantástica de lengua española", en Teoria semiótica, op. cit., pp. 423-431. 
fácilmente reconocible - «'effet de réel», como decía Barthes--, o la verosimilitud que comporta la credibilidad ${ }^{20}$. Es, por tanto, el lector, deseoso de ilusión, quien establece la relación de analogia (o de identidad) entre el mundo imaginario y el mundo referido, que le es familiar. Es él quien «reconoce" ( = cree reconocer) en el texto la "realidad». En cuanto al sujeto enunciante, la realidad imaginativa puede servirle de base para una discusión ideológica en torno a los valores vigentes en el mundo referido. De lo dicho se infiere que no cabe buscar la verdad de la literatura en la correspondencia entre lo representado y lo referido (identificación que - lo repito- sólo se produce en la imaginación del lector), sino en los valores afirmados como auténticos por el texto, con tal que dicha afirmación no sea invalidada ulteriormente por medio de la ironía. Este es el caso en una obra que todo hispanista conoce: el Quijote, cuyo enunciador no asume ni la verdad del protagonista ni la de la sociedad (antagonista), dejando la solución a cargo del lector. Estamos, pues, frente a un texto sustentado por una poética irónica, que rehúsa dar la entera razón a ninguno de los contrincantes, ni al generoso idealista sospechoso de locura, ni tampoco al realismo mezquino de quienes se consideran "cuerdos" ${ }^{21}$.

Pero si la literatura no reproduce, sino produce - y anula - verdad(es), ¿cuál podrá ser la relación que mantiene con otros discursos, tradicionalmente reputados de verídicos, tales como la historia o las ciencias naturales? La relación entre la semiótica y la historia continúa siendo un tema de debates apasionados, pese a que los historiadores más avanzados estén dispuestos hoy a admitir el carácter a su vez problemático del concepto de verdad histórica. Gracias a la aparición de nuevos enfoques sociocríticos, de inspiración bajtiniana o lotmaniana, ha podido desvirtuarse el reproche de que la semiótica, con su afán de inmanencia y de sistemas coherentes cerrados, proponga interpretaciones del todo ajenas a la realidad del devenir histórico ${ }^{22}$. La semiótica contemporánea no sólo no quiere ser anti- o ahis-

${ }^{20}$ Sobre el concepto de «effet de réel» (introducido por Barthes) véase el estudio critico de A. Ruffinatto, "Effetti di reale. Cronaca di un abbaglio con il Chisciotte sullo sfondo», en Semiótica Ispánica. Cinque esercizi, Alessandria, Ed. dell'Orso, 1985.

${ }^{21}$ Sobre la diferencia entre verdad y verosimilitud en el Quijote: J. F. Canavaggio, «Alonso López Pinciano y la estética literaria de Cervantes en el Quijote», Anales Cervantinos, 7, 1958 , pp. 13-107; J. Marías, «La pertinencia de El curioso impertinente», en Obras, III, Madrid, 1959, pp. 306-311; y G. Güntert, «El lector defraudado. Conocer y creer en el Curioso impertinente», Romanistisches Jahrbuch, XXXVII, 1986, pp. 265-281.

${ }_{22}$ P. Berger y Th. Luckmann, La construcción social de la realidad, Buenos Aires, Amorrortu, 1968; A. Schutz, El problema de la realidad social, Buenos Aires, Amorrortu, 1974; A. Roche, "Histoire et littérature: un projet", en Littérature, 13, 1974, pp. 22-28; P. V. Zima, Pour une sociologie du texte littéraire, París, 10/18, UGE, 1978; F. Basaglia et al., Razón, locura y sociedad, México, Siglo XXI, 1978; P. Aage Brandt, "Discurso, modalidad y subjetividad. Notas para una semiótica social», Semiosis, 5, 1980, pp. 3-37; E. Trabulse, "En torno al Discurso histórico", Discurso. Cuadernos de teoria y análisis, 2, 1983, México, UNAM, pp. 8-20. 
tórica, sino que postula, con el concepto de pluridiscursividad, la copresencia de diferentes Discursos en el texto literario, entre los cuales no faltará, pues, el Discurso social, esto es, las creencias dominantes en la sociedad de la que el texto (y su autor) proceden. Es indispensable, naturalmente, una distinción esclarecedora entre la sociedad de la obra y la sociedad de referencia: la primera es la sociedad interna de la obra, construida imaginariamente; la segunda es la experimentada por el autor, el contexto social en el cual se inscribe su obra.

La semiótica contemporánea no es, pues, indiferente a las preocupaciones de la historia y a las reivindicaciones sociales. Si el formalismo de los años sesenta pudo ser considerado como una variante del idealismo, en la medida en que sus primeros representantes occidentales (Todorov, Brémond, Barthes) desatendían los condicionantes histórico-sociales de la producción literaria, tal reparo no podría ponerse a la semiótica actual, bien consciente de que cada texto literario remite a un mundo polifónico y pluridiscursivo que se manifiesta —a veces polémicamente- en él.

3. Y venimos al tercer punto. Cuando se intenta abordar el problema de las relaciones entre literatura, semiótica y otras disciplinas, se tropieza inevitablemente con la cuestión de la especificidad del discurso literario. Es mérito de Roman Jakobson el haber definido, ya desde su famoso trabajo de 1921 sobre la nueva poesía rusa, la función estética, que confiere autonomía al lenguaje poético frente al cotidiano, en cuanto sus representaciones verbales logran atraer la atención sobre sí mismas, estrechándose el nexo entre fonemas y significados ${ }^{23}$. Del concepto de función estética propuesto en 1921, Jakobson llegó —en los años treinta (1933/34) - a formular el de poeticidad, un componente —dominante, según él, en el lenguaje literarioque hace que éste remita preferentemente a si mismo. La dificultad de adoptar este concepto consiste en el hecho de que la misma función expresiva actúa también en otros actos comunicativos, hallándose, por ejemplo, en los mensajes publicitarios o en los discursos concebidos para ceremonias sociales, textos que ni remotamente podemos empadronar en la literatura. Definida de este modo, la «literariedad» se ve hoy afectada por un aluvión de escepticismo. Un estudio reciente se titula La crisis de la literariedad, y la palabra «crisis», con respecto a este concepto, aparece en casi todos los

${ }^{23}$ Cfr. sobre este tema los dos estudios críticos de F. Lázaro Carreter, «Función poética y verso libre» y «¿Es poética la función poética?», ambos en Estudios de poética. Madrid, Taurus, 1976. Una inteligente y cuidadosa comparación de las teorías jakobsonianas con otras. más recientes, se encuentra en J. M. Pozuelo Yvancos, La lengua literaria, Málaga, Ágora. 1983. 
manuales de esta década ${ }^{24}$. No por esto se han dejado de buscar nuevas definiciones de la función estética, confiando en que ésta podría ser, a pesar de todo, un rasgo distintivo del discurso literario y, más generalmente, artístico. Pienso, por ejemplo, en el último estudio de A. García Berrio, Teoria de la literatura, cuyo autor se complace en "nadar contra corriente» al proponer nuevamente los términos de literariedad, poeticidad, expresividad, y - nota bene- sin confundirlos uno con otro ${ }^{25}$.

Para los seguidores del Círculo de Praga y de Hjelmslev, en especial, lo literario se reduce a ciertas marcas formales que, en vez de funcionar primordialmente en el plano de la denotación, como ocurre en el lenguaje corriente, potencian los elementos connotativos del texto, cuya finalidad no es informar, sino jugar con las polivalencias expresivas del lenguaje ${ }^{26}$. De ahí que el uso literario de la connotación (concepto elaborado desde los años treinta por algunos lingüistas) se entronque con otras teorías que definen la literariedad como «écart», como desviación o transgresión de la norma - un concepto familiar a la crítica estilística, que a su vez postulaba un uso «particular» del lenguaje en el dominio poético-literario-. Pero ¿es la poesía ese uso particular del lenguaje o acaso es, por el contrario, la plena manifestación de sus posibilidades expresivas??

A nuestro modo de ver, los fenómenos de la poeticidad y la función connotativa se presentan de manera gradual en los textos, sin poder constituir un criterio diferenciador del discurso literario, cuyo carácter específico parece depender, por otra parte, de un complejo sistema de convenciones o de códigos. En su Teoría literaria, Susana Reisz de Rivarola somete a nueva prueba el concepto lotmaniano de metatexto, concluyendo que el texto debe verse «en relación con un metatexto que lo clasifica como tal y lo ordena dentro de una tipología, proyecta sobre él un valor y orienta su codificación según una compleja jerarquía de normas pertenecientes a distintos códigos secundarios que se superponen a las del código primario de la lengua natural» ${ }^{28}$.

${ }^{24}$ M. A. Garrido Gallardo, T. Todorov et al., La crisis de la literariedad, Madrid, Taurus, 1987; J. M. Pozuelo Yvanco, La lengua literaria, op. cit., cap. V; «La crisis de la literariedad en las poéticas textuales», pp. 61-81; J. Talens, "Teoría y técnica del análisis poético", en J. Talens, J. Romera Castillo, A. Tordera y V. Hernández Esteve, Elementos para una semiótica del texto artístico, Madrid, Cátedra, 1980, pp. 70-73.

25 A. Garcia Berrio, Teoria de la literatura, Madrid, Cátedra, 1989.

${ }^{26}$ L. Hjelmslev, Omkring Sprogteoriens Grundlaeggelse, Copenhague, 1943 (trad. española publicada por la ed. Gredos, Madrid, en 1971). Cfr. también: J. A. Martínez, Propiedades del lenguaje poético, Oviedo, Universidad, 1975; B. Garza Cuarón, La connotación: problemas del significado, México, Colegio de México, 1978; J. M." Pozuelo Yvancos, «La teoría de la connotación", en Teoria del lenguaje literario, Madrid, Cátedra, 1988.

${ }^{27}$ E. Coseriu, «Tesis sobre el tema Lenguaje y poesia», en El hombre y su lenguaje, Madrid, Gredos, 1977 (ed. original de 1971).

${ }^{28}$ S. Reisz de Rivarola, en Teoria literaria..., op. cit., p. 44, remite a Y. Lotman, "The 
Por otra parte, desde el campo de los adversarios del idealismo (neomarxistas, antropólogos, adeptos de la sociocrítica) se alzan hoy nuevos vetos a una idealización de la literatura: la intención de estos últimos $-\mathrm{y}$ pienso en Claude Duchet, Gilberto Giménez, Alejandro Losada- es comprender las formas literarias como prácticas sociales, susceptibles de integrarse en el conjunto de las restantes (políticas, juridicas, publicitarias) mediante su inscripción en una teoría de los modos de simbolización ${ }^{29}$. No se trataria ya de insistir en los rasgos diferenciadores para separar el quehacer literario de las demás actividades culturales, sino, antes al contrario, de aunar $-\mathrm{y}$ describir - los elementos que todas estas actividades tienen en común. Esta propuesta puede resultar tanto más estimulante en culturas mixtas como la andina o la mejicana, en cuanto que en ellas coexisten, al lado de los sistemas cultos y tradicionalmente privilegiados, sistemas estéticos populares basados en la oralidad y subvalorizados durante mucho tiempo. Ante situaciones semejantes, el protagonismo de la literariedad dentro del debate crítico es, a todas luces, improcedente, y no es de lamentar que tal concepto haya dejado de ser la preocupación central para los teóricos de la literatura.

content and structure of the concept of literature», PTL, I, 2, 1976, pp. 339-356. Cfr. del mismo autor Die Struktur des künstlerischen Textes (Struktura chudozestvennogo teksta). Francfort/ M., Suhrkamp, 1973.

${ }_{29}$ C. Duchet, "Une écriture de la socialité», Poétique, 16, 1973, pp. 446-454; id., «Pour une sociocritique ou variation sur un incipit", Littérature, 1, 1971, pp. 5-14; G. Giménez, "Lingüistica, semiología y análisis ideológico de la literatura", en AA.VV., Literatura, ideología y lenguaje, México, Grijalvo, 1978, pp. 270-275; id., "Nuevo enfoque sociológico de la semiótica literaria", Semiosis, 3, 1979, pp. 103-119; A. Losada, La literatura en la sociedad de América Latina. Estrategias de investigación. Universidad de Odense, 1981; cfr. también el número monográfico de la Revista de Critica Literaria Latinoamericana, 17, 1983, coord. por A. Losada, sobre el tema «Sociedad y literatura en América Latina». Una bibliografia de sus escritos se encuentra en la necrología redactada por M. Lienhard, I. Phaf, J. Morales Saravia "Alejandro Losada", Revista Iberoamericana, 135/136, 1986, pp. 631-644. 